\title{
Functional Compatibility of Local Flaps for Coverage of Digital Skin Defects
}

\author{
Ayesha Aslam, Sameena Aman, Nousheen Saleem, Ahmed Ali, Samia Rizwan and Anum Ikram \\ Department of Plastic Surgery, Fauji Foundation Hospital, Rawalpindi, Pakistan
}

\begin{abstract}
Objective: To determine if local flap coverage is functionally compatible of digital defects.

Study Design: Observational study.

Place and Duration of Study: Department of Plastic and Reconstructive Surgery, Fauji Foundation Hospital, Rawalpindi, from January 2017 to June 2019.

Methodology: Patients with small and medium skin defects on digits were included. Data was collected for both independent and dependent variables, emphasising on functional outcome based on five parameters (adequate coverage of the defect, functional length of the digit, painless scar, finger-tip sensation, and inter-phalangeal joint motion). Follow-up was done for six months.

Results: Total number of patients included in the study was 96 , with 45 male and 51 female patients. Mean age of study participants was $26.6 \pm 16.9$ years. Small to medium size defects were included in the study for coverage by local flaps like cross figure, lateral proximal phalanx, flag, thenar, homo-digital flaps etc. Results were studied in terms of functional outcomes. All the five parameters were achieved in 84 (87.5\%) patients. Complications were observed in 10 (10.4\%) patients. The most frequent complication was wound infection, which was observed in $2(2.1 \%)$ patients.
\end{abstract}

Conclusion: Local flaps for finger defects are a very effective way of providing durable soft tissue coverage.

Key Words: Digital defects, Digital reconstruction, Local flaps for digits, Hand injuries.

How to cite this article: Aslam A, Aman S, Saleem N, Ali A, Rizwan S, Ikram A. Functional Compatibility of Local Flaps for Coverage of Digital Skin Defects. J Coll Physicians Surg Pak 2022; 32(01):92-95.

\section{INTRODUCTION}

The hand is a specialised organ. Its function depends upon an intricate balance of its soft tissue covering and underlying structures. ${ }^{1}$ Its role in day-to-day activities makes it vulnerable to frequent injuries. ${ }^{2-4}$ These injuries often lead to soft tissue loss, requiring coverage to restore its function as well as appearance. $^{5}$

Various techniques have been described in the literature for the soft tissue coverage of the digital defects. As plastic surgery evolved, so did these techniques. ${ }^{6}$ The choice of technique depends upon number of factors, like size of the defect, type of the defect, available donor areas, and surgeon's expertise etc. $^{7}$

Correspondence to: Dr. Ayesha Aslam, Department of Plastic Surgery, Fauji Foundation Hospital, Rawalpindi, Pakistan

E-mail: whitepearl2003@yahoo.com

Received: January 04, 2021; Revised: March 21, 2021;

Accepted: April 28, 2021

DOI: https://doi.org/10.29271/jcpsp.2022.01.92
The abundance of options sometimes leads to confusion in choosing the best option, especially to the novice mind. The question arises which technique is better for a particular defect that fulfills all the goals of reconstruction, and achieves adequate coverage in minimal time and with least donor-site morbidity. ${ }^{8-10}$ The purpose of this study was to analyse cases of digital hand injuries, amenable to coverage by local flaps for its functional compatibility.

\section{METHODOLOGY}

It was a prospectively conducted, observational study done in the Department of Plastic Surgery, Fauji Foundation Hospital, Rawalpindi after approval from the hospital's Ethical Committee. The study period was from January 2017 to June 2019. All patients presenting to the Plastic Surgery Department with small to medium size skin defects of digits (small being 1.5 $\mathrm{cm}$ or less, and medium being 1.5 to $3 \mathrm{~cm}$ in widest dimension) and a minimum follow-up of six months post-surgery. Exclusion criteria were, use of a hybrid technique (graft plus flap) and extensive damage, i.e. of more than three structures of the digit.

All the flaps were performed in a standard fashion. The independent variables studied were age, gender, etiology of the defect, location of the defect, size of the defect, and type of local flap used. The dependent variables included were complications \& 
functional outcome. The functional outcome was studied, based on five factors which were: ability of the flap to adequately cover the wound, painless scar, ability to preserve functional length of the digit, sensibility of the fingertip, and preservation of inter-phalangeal joint motion. Adequate coverage of the wound was taken sufficient, if more than $95 \%$ of the original wound was covered with the flap and healed without secondary intention. Pain in the scar was recorded using visual analogue scale of 0 to 10 , and was studied at the end of six months after the surgical intervention. The functional length of the digit was taken as more than or equal to the $90 \%$ of original. Sensibility of the fingertip was assessed using two point discrimination and was labelled as sufficient, if it is $10 \mathrm{~mm}$ or less at the end of six months. Preservation of inter-phalangeal joint motion was taken as adequate, if it was $90 \%$ or more of the full range of motion of that joint (examined by goniometer).

Data was entered and analysed using SPSS version 22. Numerical variables were described as mean \pm SD and categorical variables were described as frequencies and percentages.

Table I: Baseline information.

\begin{tabular}{|c|c|}
\hline Age (mean years \pm SD) & $26.6 \pm 16.9$ \\
\hline \multicolumn{2}{|l|}{ Age groups $n(\%)$} \\
\hline$\leq 18$ years & $35(36.5)$ \\
\hline $19-50$ years & $52(54.2)$ \\
\hline$>50$ years & $9(9.3)$ \\
\hline \multicolumn{2}{|l|}{ Gender n (\%) } \\
\hline Males & $45(46.9)$ \\
\hline Females & $51(53.1)$ \\
\hline \multicolumn{2}{|l|}{ Size of defect $n(\%)$} \\
\hline Small & $59(61.5)$ \\
\hline Medium & $37(38.5)$ \\
\hline \multicolumn{2}{|l|}{ Etiology n (\%) } \\
\hline Post contracture release & $52(54.2)$ \\
\hline Acute trauma & $31(32.3)$ \\
\hline Tumor excision & $3(3.1)$ \\
\hline Miscellaneous & $10(10.4)$ \\
\hline \multicolumn{2}{|l|}{ Location } \\
\hline Volar digital & $68(70.8)$ \\
\hline Volar and dorsal thumb & $12(12.5)$ \\
\hline Dorsal digital & $10(10.4)$ \\
\hline Web space & $6(6.3)$ \\
\hline \multicolumn{2}{|l|}{ Type of flaps } \\
\hline Cross finger flap & $22(22.9)$ \\
\hline Z plasty & $21(21.9)$ \\
\hline Lateral proximal phalanx flap & $18(18.8)$ \\
\hline V-Y advancement & $8(8.3)$ \\
\hline DCMA flap ${ }^{*}$ & $7(7.3)$ \\
\hline Flag flap & $7(7.3)$ \\
\hline Thenar flap & $5(5.2)$ \\
\hline Homodigital flap & $4(4.2)$ \\
\hline Moberg flap & $4(4.2)$ \\
\hline
\end{tabular}

Binary logistic regression analysis was applied for estimation of adjusted odds ratios (OR) or confidence intervals (CI) of OR for different variables and their independent influence on functional outcomes and complications. The significance level was setat $p \leq 0.05$.

\section{RESULTS}

Total number of patients, who fulfilled the inclusion criteria, were 96 . The mean age of study participants was $26.6 \pm 16.9$ years. Other baseline information is tabulated in Table I. All the functional outcomes were achieved in 84 (87.5\%) patients (Tablell, Figures 1-3).

Complications were observed in $10(10.4 \%)$ patients. The most frequent complication was wound infection, which was observed in $4(4.1 \%)$ patients. Other complications are mentioned in Tablell.

Table II: Functional outcome achieved and complications observed.

\begin{tabular}{|l|l|}
\hline Complications & n (\%) \\
\hline Wound infection & $4(4.1)$ \\
\hline Problematic scar & $3(3.1)$ \\
\hline Wound dehiscence & $3(3.1)$ \\
\hline Donor site graft loss & $2(2.0)$ \\
\hline Complete flap loss & $2(2.0)$ \\
\hline Partial flap loss & $2(2.0)$ \\
\hline Joint stiffness & $2(2.0)$ \\
\hline Functional outcome achieved (\%) & $94(97.9)$ \\
\hline Adequate functional length & $93(96.9)$ \\
\hline Adequate coverage & $93(96.9)$ \\
\hline Painless scar & $92(95.8)$ \\
\hline Range of Inter phalangeal joint motion & $45(66.17)$ \\
\hline Adequate sensation of fingertip
\end{tabular}

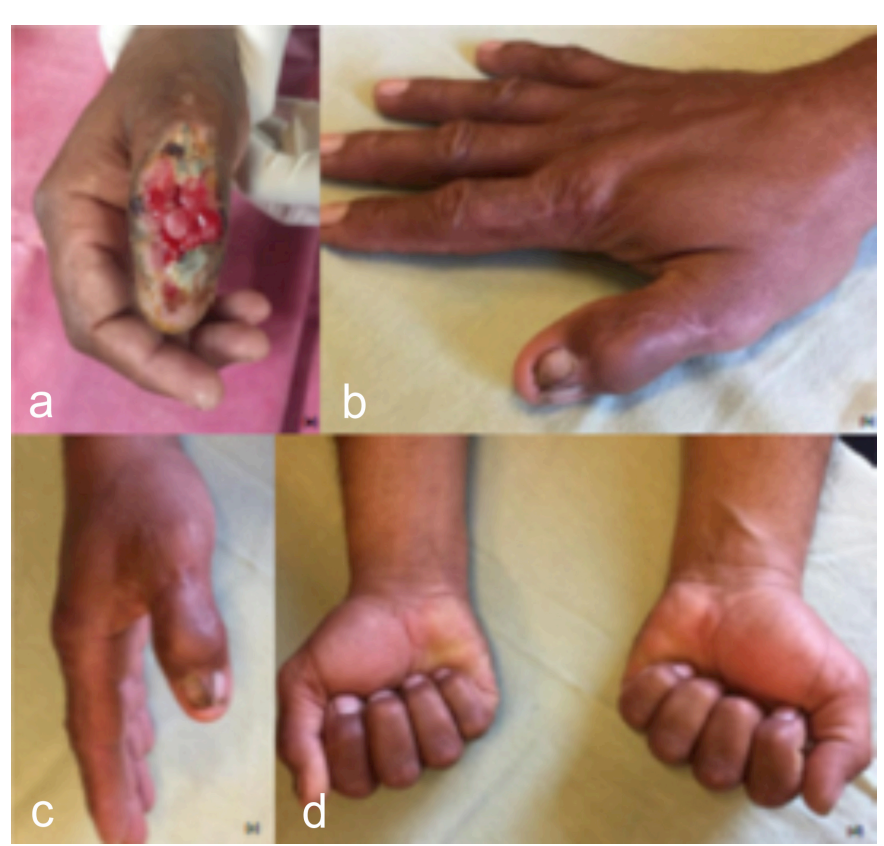

Figure 1: (a) Preoperative picture; (b, c) Well healed Flag flap and donor site, (d) Good functional recovery. 


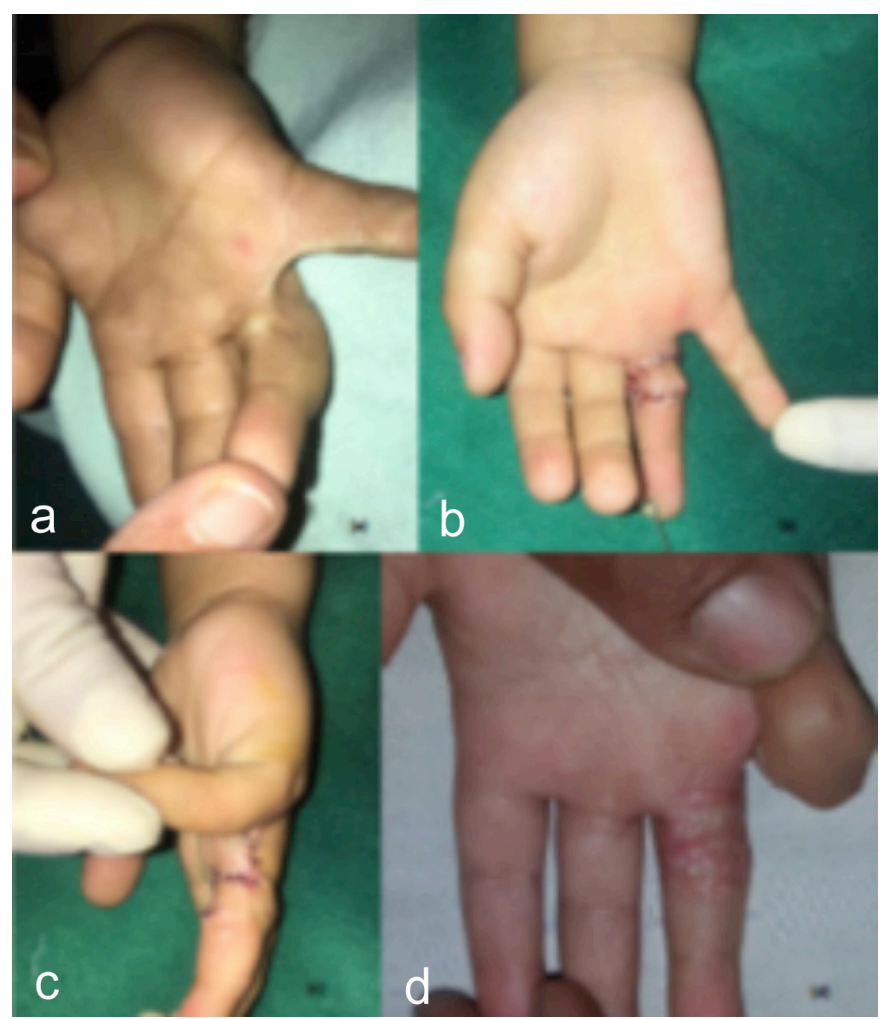

Figure 2: (a) Post-burn flexion contracture; (b) Lateral proximal phalanx flap; (c) Lateral view showing donor site; (d) Well healed flap.

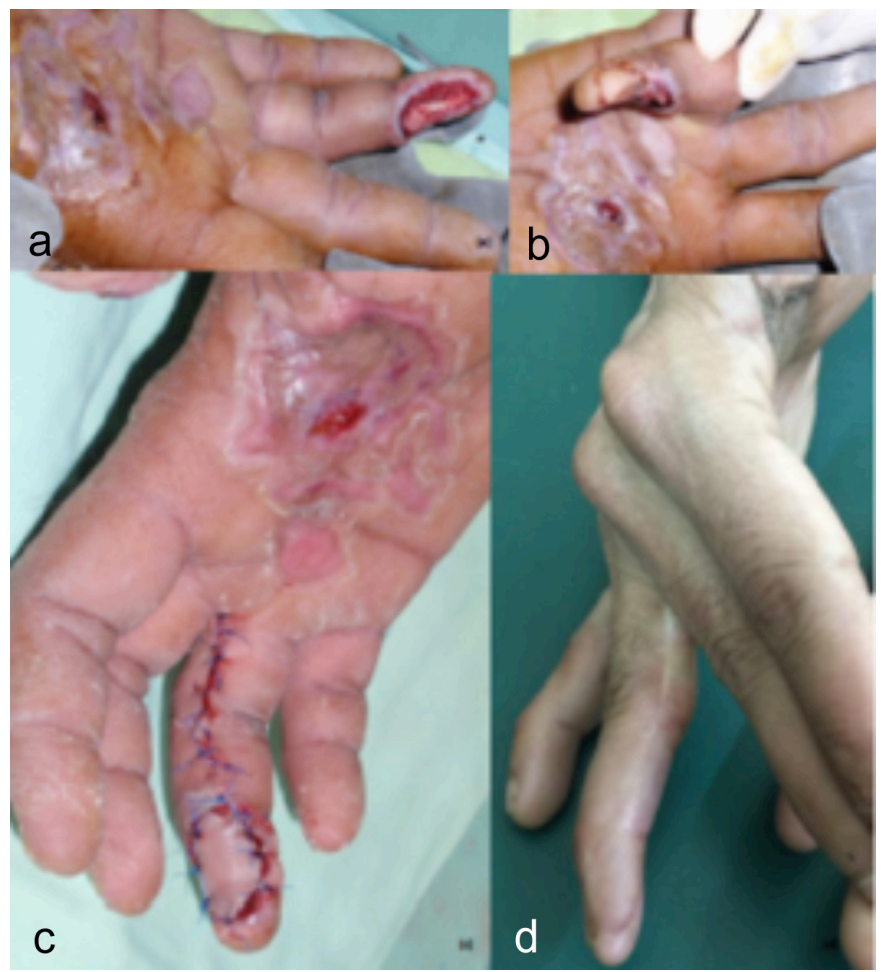

Figure 3: $(a, b)$ Soft tissue defect on volar and lateral aspect of ring finger; (c) Homo digital island flap in place; (d) Well-healed flap.

There was no independent influence of any single variable on complication rate and in cases where all functional outcomes were not achieved after adjustmentfor other variables.
Significance of modifier was $p=0.553$ for age effect, $p=0.750$ for gender, $p=0.584$ for size of defect, and 0.393 for the type of flap.

\section{DISCUSSION}

Soft tissue digital defects are one of the commonest reconstructive problems seen by a plastic surgeon. ${ }^{8}$ To date, researchers are coming up with the new ideas, in quest of achieving an ideal coverage of these functionally important and cosmetically sensitive areas. ${ }^{11}$ This study was based on the evaluation of the commonly done procedures for these defects.

About $70 \%$ of these defects were on the volar side of the digits, which were mostly covered by cross finger flap. It can cover small to moderate size defects effectively with a modification to make it sensate. The main drawbacks are: use of skin graft for a visible donor site, procedure being two-staged and joint stiffness. Immediate mobilisation after this flap, results in early return to work due to less joint stiffness. ${ }^{12}$ In this series, the overall residual joint stiffness was observed in only $2 \%$ of the patients. The protocol was to start the rehabilitation after one week of suture removal.

The overall outcome in which all five parameters were achieved was $87.5 \%$ with the main aim being resumption of daily activities in a shorter time and with minimal short term and long term complications. ${ }^{13-15}$ These local flaps were able to achieve adequate wound coverage in almost $97 \%$ of defects making them a very reliable coverage option. Jiao et al. in their article of clinical experience of multiple flaps for the reconstruction of dorsal digital defects achieved adequate coverage with minimal complications. ${ }^{1}$

Loss of digital length contributes in weakening of grip. ${ }^{16}$ Though the best way to preserve the length is by replantation, it is not always feasible. ${ }^{17,18}$ This series showed that the adequate functional length of the digits was preserved by the use of these local flaps in almost $98 \%$ of the patients, which shows that the local flaps are quite effective in distal digital coverage. Thus, every effort should be made to avoid shortening and primary closure of distal stump and a potential painful scar. ${ }^{19}$

The infections were managed with the culture-specific antibiotics and general wound care. There was total flap loss in $2 \%$ cases ( 2 patients), which ultimately required secondary procedures. Both of these cases were of lateral proximal phalanx flap. Karjalainen et al. in their series of 851 cases of local flaps for fingertip reconstruction reported an unplanned secondary surgery in $3.6 \%$ of their cases. ${ }^{20}$

The strengths of this study are that it was planned as prospective with adequate number of patients and a reasonable duration of follow-up to derive results from, studying all important aspects of functional outcomes. Its weaknesses are that it does not address the patient satisfaction and aesthetic outcomes of these local flapsfor digital defect coverage. 


\section{CONCLUSION}

Local flap for finger defect reconstruction is a very effective way of providing durable soft tissue coverage. It requires less operating time and expertise. However, these procedures are limited for small to moderate size defects.

\section{ETHICAL APPROVAL:}

Ethical approval was taken before the start of the study from hospital's ethical committee.

\section{PATIENTS' CONSENT:}

Informed consent from the patients and parents in case of minors was taken regarding use of data for publication including photographs.

\section{CONFLICT OF INTEREST:}

The authors declared no conflict of interest.

\section{AUTHORS' CONTRIBUTION:}

AA: Conception/design, drafting, data analyses, interpretation. SA: Critical revision of the article, design and data analyses.

NS: Data collection, drafting.

AA, SR, Al: Data collection.

All the authors approved the manuscript for the publication.

\section{REFERENCES}

1. Jiao $H$, Ding $X$, Liu $Y$, Zhang $H$, Cao X. Clinical experience of multiple flaps for the reconstruction of dorsal digital defects. Int J Clin Exp Med 2015; 8(10):18058-65.

2. Bhatti DS, Ain NU, Fatima M. Occupational hand-related injuries at a major tertiary care burn and reconstructive center in Pakistan. Cureus 2020; 12(9):e10444. doi: 10.7759/cureus.10444.

3. Karakas AO, Yuce E. Evaluation of pediatric fingertip injuries using etiology, demographics and therapy. Sisli Etfal Hastan Tip Bul 2020; 54(3):306-312. doi: 10.14744/SEMB.2018.82788.

4. Grivna M, Eid HO, Abu-Zidan FM. Epidemiology of isolated hand injuries in the United Arab Emirates. World J Orthop 2016; 7(9):570-6. doi: 10.5312/wjo.v7.i9.570.

5. Hu H, Chen H, Hong J, Mao W, Tian M, Wang L, et al. Propeller perforator flaps from the dorsal digital artery perforator chain for repairing soft tissue defects of the finger. BMC Surg 2019; 19(1):188. doi: 10.1186/s12893019-0649-7.

6. Feng SM, Sun QQ, Cheng J, Wang AG. A Novel approach for reconstruction of finger neurocutaneous defect: A sensory reverse dorsal digital artery flap from the neighboring digit. Orthop Surg 2017; 9(4):372-379. doi: 10.1111/os.12350.

7. Chen C, Tang P, Zhang L. Reconstruction of a large softtissue defect in the single finger using the modified cross finger flap. J Plastic Reconstr Aesthetic Surg 2015; 68(7): 990-4. doi: 10.1016/j.bjps.2015.03.033.
8. Ramirez EG, Hoyt KS. Management of Hand Injuries: Part II. Adv EmergNurs J 2016; 38(4):266-78. doi: 10.1097/TME. 0000000000000128.

9. Kostopoulos E, Agiannidis C, Konofaos P, Dounavis A, Papadopoulos O, Casoli V. Predictable pattern digital artery perforator flap: An alternative concept in digital reconstruction. Hand (NY) 2016; 11(1):88-96. doi: 10.1177/1558944715614839.

10. Lee $M$, Lee $Y K$, Kim DH. The clinical result of arterialised venous free flaps for the treatment of soft tissue defect of the fingers. Medicine (Baltimore) 2019; 98(23):e16017. doi: 10.1097/MD.0000000000016017.

11. Giladi AM, Ranganathan K, Chung KC. Measuring functional and patient-reported outcomes after treatment of mutilating hand injuries: A global health approach. Hand Clin 2016; 32(4):465-75. doi: 10.1016/j.hcl.2016.06.002.

12. Al-Qattan MM. Time of return back to work and complications following cross-finger flaps in industrial workers: Comparison between immediate postoperative mobilisation versus immobilisation until flap division. Int J Surg Case Rep 2018; 42:70-4. doi: 10.1016/j.ijscr.2017. 11.048.

13. Germann G, Rudolf KD, Levin SL, Hrabowski M. Fingertip and thumb tip wounds: Changing algorithms for sensation, aesthetics, and function. J Hand Surg Am 2017; 42(4): 274-84. doi: 10.1016/j.jhsa.2017.01.022.

14. Acharya AM, Ravikiran N, Jayakrishnan KN, Bhat AK. The role of pedicled abdominal flaps in hand and forearm composite tissue injuries: Results of technical refinements for safe harvest. J Orthop 2019; 16(4):369-76. doi: 10.1016/j. jor.2019.04.008.

15. Alawi SA, Werner D, Könneker S, Vogt PM, Jokuszies A. Quality of life and reconstructive surgery efforts in severe hand injuries. Innov Surg Sci 2018; 3(2):147-156. doi: 10.1515/iss-2018-0002.

16. Duncan SF, Saracevic CE, Kakinoki R. Biomechanics of the hand. Hand Clin 2013; 29(4):483-92. doi: 10.1016/j.hcl. 2013.08.003.

17. Huan AS, Regmi S, Gu JX, Liu HJ, Zhang WZ. Fingertip replantation (zone I) without venous anastomosis: Clinical experience and outcome analysis. Springerplus 2016; 5(1):1835. doi: 10.1186/s40064-016-3394-8.

18. Agarwal R, Agarwal D, Agarwal M. Approach to mutilating hand injuries. J Clin Orthop Trauma 2019; 10(5):849-52. doi: 10.1016/j.jcot.2019.08.011.

19. Mende K, Strub B, Meuli-Simmen C. Autologous fat grafting for painful finger scars. J Hand Surg Eur 2016; 41(2):226-7. doi: 10.1177/1753193414543194.

20. Karjalainen T, Sebastin SJ, Chee KG, Peng YP, Chong AKS. Flap related complications requiring secondary surgery in a series of 851 local flaps used for fingertip reconstruction. J Hand Surg Asian Pac 2019; 24(1):24-29. doi: 10.1142/ S242483551950005X. 